Екатерина Каляева

\title{
ЭМОЦИИ И СОЦИАЛЬНЫЕ ПРОТЕСТЫ: ЗНАЧЕНИЕ ИЗУЧЕНИЯ ЭМОЦИЙ ДЛЯ ПОНИМАНИЯ КОЛЛЕКТИВНОГО ПОВЕДЕНИЯ В СОВРЕМЕННОМ ОБЩЕСТВЕ
}

\author{
Jasper J. (2018) The Emotions of Protest. Chicago: University of \\ Chicago Press. 304 p. ISBN: 9780226561813
}

DOI: $10.17323 / 727-0634-2020-18-1-162-168$

Эмоции в социологии долгое время находились «на периферии исследовательского интереса» (Симонова 2012; Barbalet 1999). Внимание к этой теме (и формирование социологии эмоций как области знаний) возросло в 1970-е гг., когда появились классические работы Арли Хохшильд, Томаса Шеффа и Рэндалла Коллинза. Положение дел в этом поле сегодня можно обозначить как «эмоциональный поворот»- обращение «к эмоциональному измерению социальных явлений и одновременно к социальной природе эмоциональных состояний» (Симонова 2016а: 13). Социологи рассматривают эмоции как важнейший аспект жизни общества, который нельзя игнорировать.

Эмоции в социологии социальных движений- одно из активно разрабатываемых направлений исследований (Jacobsson, Lindblom 2012; Goodwin, Jasper 2006; Ferree et al 2004; Gould 2004; Kemper 2001). Тема социальных движений тесно связана со сферой социальной политики через акценты на борьбе людей за социальные права, улучшение жизни населения и дискриминируемых групп. В современном политическом словаре социальные движения все чаще называются протестными, потому что в их основе лежит то или иное несогласие с текущим положением дел. На изучении эмоций в рамках социальных протестов фокусируется один из лидеров в данной проблематике американский социолог Джеймс Джаспер, профессор городского университета Нью-Йорка.

Своей книгой «Эмоции социальных протестов» автор поднимает вопрос о значении эмоций для понимания протестных акций. Именно протестных, а не социальных движений в целом, так как социальные движения в своем первоначальном виде практически перестали существовать и преимущественно перевоплотились в протестные акции. Автор употребляет понятие «социальные движения» только во введении и затем фокусируется на протестах. Эта проблематика актуальна и для современного российского

Екатерина Николаевна Каляева- аспирантка, департамент социологии, Национальный исследовательский университет «Высшая школа экономики», Москва, Россия. Электронная почта: ekalyaeva@hse.ru 
общества, где активисты, чьим идеалом является демократия, объединяются с целью отстоять свои права (Клеман и др. 2010).

Джаспер предпринимает попытку обосновать необходимость анализа эмоций в данном контексте посредством трех ключевых положений исследования протестов. (1) Факт проявления эмоций на различных аренах коллективного действия (митинги, марши) и со стороны различных акторов данных взаимодействий. На политических аренах эмоции проявляются не только у самих участников акций, но, например, и полицейские испытывают эмоции (скажем, злость), а представители СМИ- гордость за освещение важных политических вопросов (Р. 161). (2) Анализ эмоций помогает показать, что является социальным протестом, а что- нет. Джаспер убежден, что для объяснения феномена протеста ключевую роль играют не его акторы, а их эмоции (Р. 163). Поэтому для понимания коллективных действий протестного характера важен не анализ взаимодействия между политическими структурами, а изучение отношений между отдельными индивидами внутри протеста. Автор сосредотачивается на разработке стратегического подхода к исследованию компромиссов или конфронтаций, основанных на эмоциях. (3) Влияние эмоций на формирование протестов при переходе с микро- на макро- уровень. Опираясь на исследования Коллинза (Collins 2004), Джаспер утверждает, что политика состоит из цепочек взаимодействий, в которых значимую роль играют эмоции. Для протестующих эти цепочки могут начинаться с разговоров на кухне, переходить к обсуждению между соседями и затем выталкивать участников на улицы города (Р. 164). Такие цепочки практически никогда не прекращаются, так как люди могут переходить из одних организаций в другие, с микро- на макроуровень взаимодействия. Задача исследователя- идентифицировать эмоции и настроения этих взаимодействий, чтобы понять, где будет накапливаться эмоциональная энергия, которая в перспективе может привести к протесту. Джаспер стремится показать, что «эмоции являются причинными механизмами многих культурных», политических и протестных движений (Р. 166). Он подтверждает свои положения примерами политического переворота в Египте, социальных движений во время президентства Буша в США и другими.

С целью изучения социально-политических протестов Джаспером была разработана авторская классификация эмоций ${ }^{1}$, которая впитала другие имеющиеся типологии (Bericat 2016; Kemper 2011; Turner 1999). Большое количество существующих в этой области знания классификаций «не являются однозначными и не исчерпывают всего разнообразия эмоций» (Симонова 2016а). В этом смысле классификация Джаспера является уникальной. С его точки зрения, рефлексные эмоции (reflex emotions) представляют собой

\footnotetext{
${ }^{1}$ Перевод типологии эмоций на русский язык предложен на основании работы О.А. Симоновой (2016a: 18).
} 
мгновенную, краткосрочную реакцию на происходящие события, возникают в условиях политических процессов и протекают внутри продолжительных эпизодов действий. Например, во время марша активисты возбуждают гнев путем повторения криков. Используя такую рефлексную эмоцию как гнев, группы протеста могут добиться возникновения длительного возмущения. В свою очередь лидеры протеста могут использовать это возмущение, чтобы помочь участникам проявить гнев на митингах и маршах (Р. 46).

Эмоции, связанные с телесными нуждами (urges) также являются кратковременными, вызванные телесными потребностями, способны вытеснять другие чувства до тех пор, пока потребности не будут удовлетворены. Они, например, возникают в условиях, когда участники не спали сутки во время протеста. Некоторые политики могут использовать этот тип эмоций (усталость, голод) против участников протеста с целью его подавления.

Настроения (moods) - это возбуждение/энтузиазм или фоновые слабо осмысленные чувства, которые обычно не имеют прямого объекта, могут быть изменены рефлексными эмоциями или другими причинами и факторами в процессе взаимодействий. Иногда сложные настроения (например, общая подавленность), встраиваясь в протест, образуют так называемый эффект «нечего терять» (Р.96) и могут привести, например, к вандализму. В то же время настроения могут не только отражать настоящее положение дел, но и намечать контуры того, что может происходить в ближайшем будущем. Например, в хорошем настроении мы ожидаем позитивные результаты, как от своих действий, так и от других людей.

Аффективные приверженности (affective commitments)- относительно стабильные позитивные или негативные чувства, направленные на другие объекты, ценности, которые обеспечивают коллективную идентичность. Аффективные приверженности анализируются более детально, чем рассмотренные ранее типы эмоций, так как связаны с феноменом социальной солидарности (Гофман 2012). Социальные связи чрезвычайно важны для жизни в обществе, а субъективный аспект солидарности выражается в «эмоциональной приверженности группе, внутригрупповым ценностям и нормам» (Симонова 2016b). Аффективные приверженности представляют собой больше, чем позитивный или негативный кластер чувств: это не только любовь и ненависть, но и доверие, уважение, ресентимент и некоторые виды страха, например, страх потери социальных связей. Джаспер рассуждает об эффекте группового мышления, групповой идентичности, доверии, и о том, какое место здесь занимают эмоции данного типа. К примеру, чувство групповой идентичности и солидарности, проявляющееся в любви и преданности лидеру или соратникам по движению, может объяснить, почему в движениях и протестах мы доверяем людям, которых больше никогда не увидим (Р. 115).

Моральные эмоции (moral emotions) - это чувства одобрения или неодобрения, основанные на моральных принципах, например, гордость или 
стыд. Аффективные приверженности и моральные эмоции являются культурным «бэкграундом», в котором возникают социальные движения. Моральные эмоции, с точки зрения автора, являются центральными в социальных движениях, они управляют индивидуальной мотивацией, помогают разграничить моральное и аморальное, справедливое и несправедливое, приемлемое и неприемлемое (Р. 158). Для коллективной идентичности такой уровень мотивации недоступен.

Для Джаспера является важным показать неразрывную связь между эмоциями и мышлением, выражающуюся в концепции feeling-thinking process (чувственно-мыслительный процесс). С одной стороны, эмоции представляют собой кратко- и долгосрочные реакции на события, а с другой, в соответствии с информативными и коммуникационными функциями эмоций- человек может осознанно ими управлять. Таким образом мы не можем рассматривать чувства без мышления и наоборот. Особого внимания заслуживает размышление о потенциале или последствиях переживаемых эмоций. Каждый тип эмоций взаимосвязан с каким-либо потенциалом: потенциалом сожаления (эмоции побуждают к действиям, о которых мы можем сожалеть впоследствии) и потенциалом разрушения (эмоции побуждают к действиям, которые могут не оправдать ожидания коллектива и способствовать разрушению социальных связей). Например, возникающее и демонстрируемое активистами отвращение может обуславливать эмоциональную реакцию других участников протеста и мешать объединению участников.

Важно упомянуть, что книга содержит полезные приложения. Первое рассматривает «эволюцию» развития изучения эмоций в политике начиная с воззрений восточных мыслителей до работ современных исследователей. Во втором- указываются методы исследования эмоций в социальных движениях и конкретные примеры их применения. По мнению Джаспера (Р. 197), в качестве основных методов исследования здесь широко используются опросы, интервью и эксперименты.

Книга представляет собой большую ценность для разных дисциплин. Многие исследователи говорят о когнитивных или ресурсных аспектах социальных движений, но Джаспер исследует культурные переменные в протестах, именно с этой точки зрения рассматривает эмоции. Книга демонстрирует, как по-новому взглянуть на явление протестных движений, изучая эмоции участников. Особую ценность представляет анализ взаимосвязи эмоций с потенциалами, которые задают направление коллективным и индивидуальным действиям. Джаспер теоретически предсказывает протестные действия через изучение этих «потенциалов». На протяжении всей книги автор доказывает, что, переосмысливая эмоции и их значение, мы можем лучше понять смысл коллективных действий, в том числе протестных.

В предложенном тексте обобщены другие исследования Джаспера и в этом смысле некоторые его положения не новы и уже рассмотрены 
в ранее опубликованных работах. Он представляет собой целостный, структурированный и систематизированный материал по проблематике эмоций в протестных движениях. Книга будет полезна как для исследователей в сфере социологии эмоций, так и для работающих в области социальной политики, протестов и социальных движений.

\section{Список источников}

Гофман А.Б. (2013) Солидарность или правила, Дюркгейм или Хайек? О двух формах социальной интеграции. Сочиологический ежегодник: 97-167.

Клеман К., Мирясова О., Демидов А. (2010) От обывателей к активистам: зарождающиеся сочиальные движения в современной России. М.: Три квадрата.

Симонова О.А. (2012) Актуальные тенденции в современной социологии: открытие эмоциональности. А. Б. Гофман, Г.В. Градосельская, И. Ф. Девятко, Д.Х. Ибрагимова, И. М. Козина, Л.Я. Косалс, В. А. Мансуров, В. Г. Николаев, О. А. Оберемко, Н. Е. Покровский, Ю.Н. Толстова, А.Ю. Чепуренко, Е.Р. Ярская-Смирнова (ред.) Современная социология - современной России: сб. ст. VI Междунар. науч. практ. конф. памяти А. О. Крыштановского. М.: Издательский дом НИУ ВШЭ: 411-423.

Симонова О.А. (2016а) Базовые принципы социологии эмоций. Вестник Санкт-Петербургского университета. Серия 12: Сочиология, (4): 12-27.

Симонова О.А. (2016b) Эмоциональная динамика социальной сплоченности в протестном поведении и социальных движениях: теоретическая перспектива. Н.Е. Покровский, М. А. Козлова (ред.) Практики сплоченности в современной России: Соииокультурный анализ. М.: Университетская книга: 338-363.

Barbalet J. M. (1999) Emotion, Social Theory and Social Structure: A Macrosociological Approach. Cambridge: Cambridge University Press.

Bericat E. (2016) The Sociology of Emotions: Four Decades of Progress. Current Sociology, 64 (3): 491-513.

Collins R. (2004) Interaction Ritual Chains. Princeton: Princeton University Press.

Ferree M. M., Ganz M., Flacks R., Gould D. B., Koopmans R., Morris A., Polletta F. (2004) Rethinking Social Movements: Structure, Meaning, and Emotion. Oxford: Rowman \& Littlefield.

Goodwin J., Jasper J. M. (2006) Emotions and Social Movements. Handbook of the Sociology of Emotions. Boston: Springer: 611-635.

Gould D. B. (2004) Passionate Political Processes: Bringing Emotions Back into the Study of Social Movements. In: J. Goodwin, J. M. Jasper (eds.) Rethinking Social Movements: Structure, Meaning, and Emotion. Oxford: Rowman \& Littlefield: 155-176.

Jacobsson K., Lindblom J. (2012) Moral Reflexivity and Dramaturgical Action in Social Movement Activism: The Case of the Plowshares and Animal Rights Sweden. Social Movement Studies, 11 (1): 41-60.

Kemper T. (2001) A Structural Approach to Social Movement Emotions. In: J. Goodwin, J.M. Jasper, F. Polletta (eds.) Passionate Politics: Emotions and Social Movements. Chicago: The University of Chicago Press: 58-73.

Kemper T.D. (2011) Status, Power and Ritual Interaction: A Relational Reading of Durkheim, Goffman and Collins. Burlington: Ashgate.

Turner J.H. (1999) Toward a General Sociological Theory of Emotions. Journal for the Theory of Social Behavior, 29 (2): 133-161. 
Ekaterina Kaliaeva

\begin{abstract}
EMOTIONS AND SOCIAL PROTESTS: THE VALUE OF STUDYING EMOTIONS FOR UNDERSTANDING COLLECTIVE BEHAVIOR IN MODERN SOCIETY
\end{abstract}

Jasper J. (2018) The Emotions of Protest. Chicago: University of Chicago Press. 304 p. ISBN: 9780226561813

DOI: $10.17323 / 727-0634-2020-18-1-162-168$

\title{
References
}

Barbalet J. M. (1999) Emotion, Social Theory and Social Structure: A Macrosociological Approach. Cambridge: Cambridge University Press.

Bericat E. (2016) The Sociology of Emotions: Four Decades of Progress. Current Sociology, 64 (3): 491-513.

Collins R. (2004) Interaction Ritual Chains. Princeton: Princeton University Press.

Ferree M. M., Ganz M., Flacks R., Gould D. B., Koopmans R., Morris A., Polletta F. (2004) Rethinking Social Movements: Structure, Meaning, and Emotion. Oxford: Rowman \& Littlefield.

Gofman A. B. (2013) Solidarnost' ili pravila, Dyurkgeym ili Khayek? O dvukh formakh so-tsial'noy integratsii [Solidarity or Rules, Durkheim or Hayek? About Two Forms of Social Integration]. Sotsiologicheskiy ezhegodnik [Sociological Yearbook]: 97-167.

Goodwin J., Jasper J. M. (2006) Emotions and Social Movements. In: Handbook of the Sociology of Emotions. Boston: Springer: 611-635.

Gould D. B. (2004) Passionate Political Processes: Bringing Emotions Back into the Study of Social Movements. In: J. Goodwin, J.M. Jasper (eds.) Rethinking Social Movements: Structure, Meaning, and Emotion. Oxford: Rowman \& Littlefield: 155-176.

Jacobsson K., Lindblom J. (2012) Moral Reflexivity and Dramaturgical Action in Social Movement Activism: The Case of the Plowshares and Animal Rights Sweden. Social Movement Studies, 11 (1):41-60.

Kemper T. (2001) A Structural Approach to Social Movement Emotions. In: J. Goodwin, J.M. Jasper, F. Polletta (eds.) Passionate politics: Emotions and social movements. Chicago: The University of Chicago Press: 58-73.

Kemper T. D. (2011) Status, Power and Ritual Interaction: A Relational Reading of Durkheim, Goffman and Collins. Burlington: Ashgate.

Kleman K., Miryasova O., Demidov A. (2010) Ot obyvateley k aktivistam: zarozhdayushchiesya sotsial'nye dvizheniya v sovremennoy Rossii [From Ordinary People to Activists: Emerging Social Movements in Modern Russia]. Moscow: Tri kvadrata.

Ekaterina N. Kaliaeva - PhD student, department of sociology, National Research University 'Higher School of Economics', Moscow, Russian Federation. Email: ekalyaeva@hse.ru 
Simonova O.A. (2012) Aktual'nye tendentsii v sovremennoy sotsiologii: otkrytie emotsional'nosti [Actual Trends in Modern Sociology: The Discovery of Emotionality]. In: A. B. Gofman, G. V. Gradosel'skaya, I.F. Devyatko, D. Kh. Ibragimova, I. M. Kozina, L. Ya. Kosals, V.A. Mansurov, V.G. Nikolaev, O. A. Oberemko, N.E. Pokrovskiy, Yu. N. Tolstova, A. Yu. Chepurenko, E. R. Yarskaya-Smirnova (eds.) Sovremennaya sotsiologiya-sovremennoy Rossii: sb. st. VI Mezhdunar. nauch. prakt. konf. pamyati A. Kryshtanovskogo [Modern Sociology- modern Russia: Sat. Art. VI International Scientific Practical Conf. in Memory of A. Kryshtanovsky.]. Moscow: Izdatel'skiy dom NIU VShE: 411-423.

Simonova O. A. (2016a) Bazovye printsipy sotsiologii emotsiy [Basic Principles the Sociology of Emotions]. Vestnik Sankt-Peterburgskogo universiteta. Seriya 12: Sotsiologiya [Vestnik SPbSU. Series 12. Sociology], (4): 12-27.

Simonova O.A. (2016b) Emotsional'naya dinamika sotsial'noy splochennosti v protestnom povedenii i sotsial'nykh dvizheniyakh: teoreticheskaya perspektiva [Emotional Dynamics of Social Cohesion in Protest Behavior and Social Movements: A Theoretical Perspective]. In: N.E. Pokrovskiy, M.A. Kozlova (eds.) Praktiki splochennosti v sovremennoy Rossii: Sotsiokul'turnyy analiz [Practices of Cohesion in Modern Russia: Socio-Cultural Analysis]. Moscow: Universitetskaya kniga: 338-363.

Turner J.H. (1999) Toward a General Sociological Theory of Emotions. Journal for the Theory of Social Behavior, 29 (2): 33-161. 